\title{
Epidemiological Review of Gastroesophageal Junction Adenocarcinoma in Asian Countries
}

\author{
Noriaki Manabe $^{a}$ Kazuhiro Matsueda ${ }^{b}$ Ken Haruma ${ }^{c}$ \\ aDivision of Endoscopy and Ultrasonography, Department of Clinical Pathology and Laboratory Medicine, Kawasaki \\ Medical School, Okayama, Japan; 'bepartment of Gastroenterology and Hepatology, Kurashiki Central Hospital, \\ Kurashiki, Japan; 'Department of General Internal Medicine 2, Kawasaki Medical School, Okayama, Japan
}

\section{Keywords \\ Gastroesophageal junction adenocarcinoma . \\ Epidemiology · Gastroesophageal reflux disease - Obesity . Helicobacter pylori}

\begin{abstract}
Background: Similar trends in the prevalence of gastroesophageal reflux disease (GERD), obesity, and Helicobacter pylori infection have been observed in Asian and Western countries despite their time differences. However, it is unclear whether the prevalence of gastroesophageal junction adenocarcinomas in Asian countries is increasing. In this review, we discuss the epidemiological trends of gastroesophageal junction adenocarcinoma in Asian countries. Summary: The prevalence of GERD is increasing in Asian countries, but most cases are considered mild. Obesity is a serious problem worldwide, but it is considered less serious in Asia than in Western countries. In Asian countries where gastric cancer is common, both cardiac and noncardiac cancers are associated with high rates of $H$. pylori infection, which is considered a carcinogenic risk factor for both sites of cancer. The widespread use of $H$. pylori eradication therapy for chronic gastritis in several Asian countries has not directly led to an increased prevalence of esophageal adenocarcinoma. One
\end{abstract}

of the originating sites of junctional adenocarcinoma in most Asian countries is Barrett's esophagus, with short-segment Barrett's esophagus having much lower carcinogenicity than long-segment Barrett's esophagus. Key Messages: Considering the future trends of several risk factors for gastroesophageal junction adenocarcinoma in Asian countries, it is likely that the incidence of gastroesophageal junction adenocarcinoma will gradually increase, but not at a rate that exceeds that of squamous cell carcinoma, as in Western countries.

(c) 2021 S. Karger AG, Basel

\section{Introduction}

In recent decades, the incidence of distal gastric carcinoma has decreased in Western countries, whereas that of gastroesophageal junction (GEJ) adenocarcinomas has clearly increased [1]. Several risk factors, such as gastroesophageal reflux disease (GERD), obesity, smoking, and low Helicobacter pylori (H. pylori) infection rates, have been associated with an increase in the prevalence of GEJ adenocarcinoma [2-5]. Nowadays, there have been several large-scale studies on risk factors for GEJ adenocarcinomas from Asian countries [6-11]. In 1999, Blaser 
proposed that the prevalence of reflux esophagitis and GEJ adenocarcinomas would increase in the future due to changes in the H. pylori infection rate [12]. Similar trends in the prevalence of GERD, obesity, and H. pylori infection were observed in Asian and Western countries, despite the time differences [13-21]. However, it is yet to be determined whether the prevalence of GEJ adenocarcinoma in Asian countries is increasing. This review article focuses on the epidemiology of GEJ adenocarcinoma in Asian countries and the differences in epidemiological trends among Japan, other Asian countries, and Western counties.

\section{Definition of the GEJ Adenocarcinoma}

GEJ carcinoma is a carcinoma in which the epicenter of the tumor is located within the GEJ region. In Japan, the Nishi classification is usually used as the definition of the GEJ region. However, the Siewert classification is widely used in Western countries. In the Nishi classification, the GEJ region is defined as the area within $2 \mathrm{~cm}$ above and below the GEJ, and the epicenter of the tumor located in this area is considered a GEJ carcinoma. Therefore, not only adenocarcinomas, but also squamous cell carcinomas, are included [22]. The Siewert classification is applied to adenocarcinomas located within $5 \mathrm{~cm}$ above or below the GEJ. The GEJ adenocarcinomas are classified as 3 types as follows. Type I which is located $1-5 \mathrm{~cm}$ above the GEJ is adenocarcinoma of the distal esophagus (almost the same as esophageal adenocarcinoma). Type II is true carcinoma of cardia centered between $1 \mathrm{~cm}$ above and $2 \mathrm{~cm}$ below the GEJ. Type III is subcardial carcinoma located 2-5 cm below the GEJ [23]. Barrett's esophageal adenocarcinoma is a carcinoma that originates from Barrett's mucosa and is mostly included in Siewert type II.

\section{Epidemiology of Esophageal Adenocarcinoma and GEJ Adenocarcinoma in Asian Countries}

Several population-based studies [1-5, 24] from Western countries have reported a rapid increase in the incidence of not only esophageal adenocarcinoma but also GEJ adenocarcinoma. Interestingly, the incidence of GEJ adenocarcinoma increased at a much slower rate than that of esophageal adenocarcinoma $[8,9]$. These 2 types of adenocarcinomas are sometimes confused because they share common risk factors [2-5]. Furthermore, GEJ adenocarcinomas have 2 different etiologies and should be examined carefully. One type is similar to distal gastric carcinoma and occurs in the background of severe atrophic gastritis; the other type is Barrett's esophageal adenocarcinoma [10]. GERD is considered an important risk factor for esophageal adenocarcinoma and GEJ adenocarcinoma [3]. It is obvious that the current increase in GERD cases in Western countries has contributed to the increased prevalence of esophageal adenocarcinoma and GEJ adenocarcinoma. In recent years, Asian countries have reported an increased prevalence of GERD [11], which is similar to the trend in Western countries. However, according to a large epidemiological study of Asian countries, the incidence of esophageal adenocarcinoma and GEJ adenocarcinoma is not as high as that in Western countries (Table 1) [25-31].

\section{Differences in the Definition of Barrett's Esophagus between Japan and Other Asian Countries}

Barrett's esophagus is believed to result from chronic gastroesophageal acid/bile reflux and is considered to predispose patients to esophageal adenocarcinoma and GEJ adenocarcinoma. In general, the incidence of Barrett's esophagus is lower in Asian countries than in Western countries [32]. However, its prevalence was reported to be as high as $43.0 \%$ in a series without biopsy in Japan [33], which is different from the results of studies conducted in other Asian countries. This discrepancy is attributed to the difference in the definition of the GEJ between Japan and other countries. Japan often uses the definition of the esophageal cancer treatment guidelines (10th edition) [34], which identifies Barrett's esophagus as the esophagus with Barrett's mucosa (a columnar epithelium extending continuously from the stomach into the esophagus, with or without intestinal metaplasia). Two types of endoscopic landmarks are used for GEJ as follows: (1) the lower margin of the palisade vessels and (2) the proximal extent of the gastric folds. In Japan, the lower margin of the palisade vessels is used as the landmark, while in Western countries, the proximal extent of the gastric folds is used. Depending on which of these landmarks is used, the rate of agreement on the diagnosis of Barrett's esophagus varies. A previous report that investigated differences in the definition of Barrett's esophagus in East Asian countries showed that the percentage of institutions using the presence of specialized intestinal metaplasia (SIM) as a criterion of Barrett's esophagus was $<50 \%$ only in Ja- 
Table 1. The incidence of esophageal adenocarcinoma and GEJ adenocarcinoma in Asian countries and in Western countries

\begin{tabular}{lll}
\hline $\begin{array}{l}\text { Geographic area } \\
\text { Pearly incidence of esophageal } \\
\text { adenocarcinoma per 100,000 } \\
\text { population (year) }\end{array}$ & $\begin{array}{l}\text { Yearly incidence of GEJ } \\
\text { adenocarcinoma per 100,000 } \\
\text { population (year) }\end{array}$ \\
\hline $\begin{array}{l}\text { America } \\
\text { North America (white) }\end{array}$ & $2.5-3.0(1991-2000)$ & $2.0-2.2(1991-2010)$ \\
$\begin{array}{l}\text { Europe } \\
\text { UK/Ireland }\end{array}$ & $4.2-4.8(2004-2006)$ & $5.4(2004-2006)$ \\
South Europe & $0.7-3.9(1992-1996)$ & - \\
$\quad$ North Europe & $1.6(2000-2007)$ & $4.0-7.0(1986-2002)$ \\
$\quad$ West Europe & $0.4-3.2(1989-1996)$ & - \\
$\quad$ East Europe & $0.5-0.7(1987-1992)$ & - \\
Australia & $4.8(1993)$ & - \\
Asia & $0.08-0.9(1998-2014)$ & $0.6-1.7(2008-2014)$ \\
$\quad$ East Asia & $0.02-0.06(1968-2002)$ & $0.5(2015)$ \\
Southeast Asia & & \\
\hline
\end{tabular}

North America: USA, Canada; North Europe: Denmark, Norway, Sweden, Finland; West Europe: Germany, the Netherlands, Switzerland; East Europe: Czech, Slovakia, Poland; East Asia: Japan, Korea, Hong Kong; Southeast Asia: Malays in Singapore. GEJ, gastroesophageal junction.

pan. However, the majority of endoscopists in other countries accepted this criterion for the diagnosis of Barrett's esophagus [35]. Because Barrett's esophagus is associated with Barrett's esophageal adenocarcinoma, different definitions of Barrett's esophagus result in different incidences of Barrett's esophageal adenocarcinoma.

The definition of Barrett's esophagus has not been standardized worldwide, and this issue needs to be resolved. The reasons for the differences in definitions include (1) the need for biopsy, (2) the length of Barrett's mucosa, and (3) differences in the endoscopic diagnosis of the GEJ. In particular, the definition of Barrett's esophagus in Japan differs from that in Western countries, except in the UK, in which the presence of a SIM is considered important [36]. Takubo et al. [37] conducted an in-depth examination of the background mucosa of endoscopic mucosal resection specimens of Barrett's esophageal adenocarcinoma and found that SIM was absent in $56.6 \%$ of the specimens. Even in Western countries, several reports have found epigenetic abnormalities in the columnar-lined esophagus without SIM. Considering these results, Barrett's esophageal adenocarcinoma does not necessarily develop only from SIM, and columnar-lined esophagus without SIM is also likely to be the origin of Barrett's esophageal adenocarcinoma.

Review of Gastroesophageal Junction Adenocarcinoma in Asian Countries

\section{Temporal Trends in Risk Factors Known to Be Associated with GEJ Adenocarcinoma in Asian Countries}

To date, several risk factors, such as GERD, obesity, smoking, alcohol consumption, male sex, Caucasian ethnicity, and low $H$. pylori infection rate, have been associated with an increased prevalence of GEJ adenocarcinomas $[2,5]$. Male sex and older people are also considered risk factors for GEJ adenocarcinoma, but the degree of the sex ratio varies by the 3 types in Western countries, but not in Asian countries. A previous report reviewed the differences in the incidence and clinicopathological features of GEJ adenocarcinoma between Western and Eastern countries. This report showed that the average age of the patients was similar in the 3 types of GEJ adenocarcinoma [38]. All types of tumors showed a male predominance. Siewert et al. [39] reported that the male-to-female ratio was 10.7 in type I, 4.9 in type II, and 2.2 in type III, with significant differences among these types. In their study, the male-to-female ratio of type II and type III in Eastern countries tended to be similar to those of Western countries, with a higher ratio of Type II patients, but the difference was not statistically significant. A recent multicenter prospective cohort study in Japan reported that the annual risk of Barrett's esophageal adenocarcinoma was $1.2 \%$ [40]. Additionally, congenital factors such as race and sex have been considered risk factors for Bar- 
Table 2. Risk factors for GEJ adenocarcinoma

\begin{tabular}{lll}
\hline Variable & $\begin{array}{l}\text { Odds } \\
\text { ratio }\end{array}$ & $\begin{array}{l}95 \% \text { confidence } \\
\text { interval }\end{array}$ \\
\hline Age $\geq 70$ years & 0.90 & $0.50-1.60$ \\
Male & 2.04 & $0.93-4.46$ \\
Esophagitis & 2.16 & $0.85-5.49$ \\
Hiatal hernia & 2.15 & $1.12-4.14$ \\
Gastric atrophy & 0.75 & $0.40-1.42$ \\
Past gastric surgery & 3.58 & $0.92-13.96$ \\
Past cholecystectomy & 6.67 & $0.76-58.26$ \\
Family history of digestive disease & 0.55 & $0.24-1.26$ \\
Smoking & 2.04 & $1.11-3.75$ \\
Drinking & 0.78 & $0.42-1.45$ \\
Obesity (BMI QUOTE $\geq 25 \mathrm{~kg} / \mathrm{m}^{2}$ ) & 3.35 & $1.62-6.93$ \\
Heart burn & 0.83 & $0.34-2.06$ \\
\hline
\end{tabular}

GEJ, gastroesophageal junction; BMI, body mass index.

rett's esophageal adenocarcinoma, and acquired factors (environmental factors) such as smoking and obesity have also been reported. According to our recent largescale epidemiological study, the incidence of GEJ adenocarcinoma, including Barrett's esophageal adenocarcino$\mathrm{ma}$, is $0.6-1.7$ per 100,000 person-years, which is lower than that in Western countries [41]. We identified hiatal hernia, obesity, smoking, and male sex as risk factors for GEJ adenocarcinoma, similar to that in Western countries (Table 2). In this review, among the identified risk factors, we focus on GERD, obesity, H. pylori infection rate, and Barrett's esophagus length in Asian countries and discuss their temporal trends.

\section{Gastroesophageal Reflux Disease}

In Asian countries, GERD was earlier considered a rare disease, but its incidence has clearly been increasing in recent years. In a recent population-based epidemiological study, the incidence of GERD was $22.2 \%$ in South India, $25 \%$ in Taiwan, $3.5 \%$ in South Korea, and $23.4 \%$ in a study of participants in a health examination program in Japan [42], and the number of cases has increased in the 2000s compared with that in the 1990s. The prevalence of GERD is increasing in Asian countries because of changes in several environmental factors and a decrease in $H$. pylori infection rates, but most cases are considered mild (Fig. 1). The increased incidence of GERD may be due in part to the increased interest in GERD among physicians and the improved diagnostic ability of endoscopic methods for GERD compared with that in the past. A study from Japan indicated that the rate of increase in
GERD incidence was higher in the early 2000s than in the 1990 s, but the rate of increase in the past decade has not been as high as that in previous decades [43]. Currently, duodenogastroesophageal reflux of bile acids is also considered to play an important role in the development of metaplasia of Barrett's esophagus and promotion of Barrett's esophageal carcinogenesis. However, the effect of bile acid sequestrants on these conditions is unclear [44].

\section{Obesity}

Until now, obesity has been considered a problem in Western countries but not in Asian countries. However, in recent decades, as Asian countries have urbanized and transportation networks have developed, people's physical activity has diminished combined with an increase in overeating, and obesity has become a social problem that cannot be ignored. According to a recent epidemiological study in Asian countries, the percentage of obese (body mass index $[\mathrm{BMI}]>25 \mathrm{~kg} / \mathrm{m}^{2}$ ) men and women was $22.9 \%$ and $24.7 \%$ in Japan [18], $43.2 \%$ and $47.4 \%$ in India, $26.9 \%$ and $31.1 \%$ in China, and $35.6 \%$ and $29.8 \%$ in Korea, respectively [10]. Cases of obesity in Asian countries are milder than those in Western countries. BMI tended to increase from 1995 to early 2000, but this has hardly changed since 2005 . Thus, obesity is a serious problem worldwide, but it is less serious in Asia than in Western countries.

\section{Helicobacter pylori}

Persistent $H$. pylori infection is believed to promote the development of gastric cancer through the development of atrophic gastritis and decrease in gastric acid secretion. However, it has a suppressive effect on GERD, Barrett's esophagus, Barrett's esophageal adenocarcinoma, and GEJ adenocarcinoma. In Western countries, $H$. pylori infection rates in cardiac cancers were found to be considerably lower than those in the control group. However, in Asian countries where gastric cancer is common, H. pylori infection rates are high in both noncardiac and cardiac cancers, and $H$. pylori infection is considered a carcinogenic risk factor for both sites of cancer [45]. In a comparison of $H$. pylori infection rates between GEJ adenocarcinoma and distal gastric carcinoma [46], the $H$. pylori infection rate in GEJ adenocarcinoma was significantly lower, and the degree of histological gastritis in the gastric body was also significantly lower. In Asian countries, including Japan, where the incidence of gastric cancer is high, 2 types of GEJ adenocarcinoma have been reported: one that is not associated with $H$. pylori infection as in Western countries and another that is associated 
Fig. 1. Trends in the incidence of GERD worldwide. GERD, gastroesophageal reflux disease.

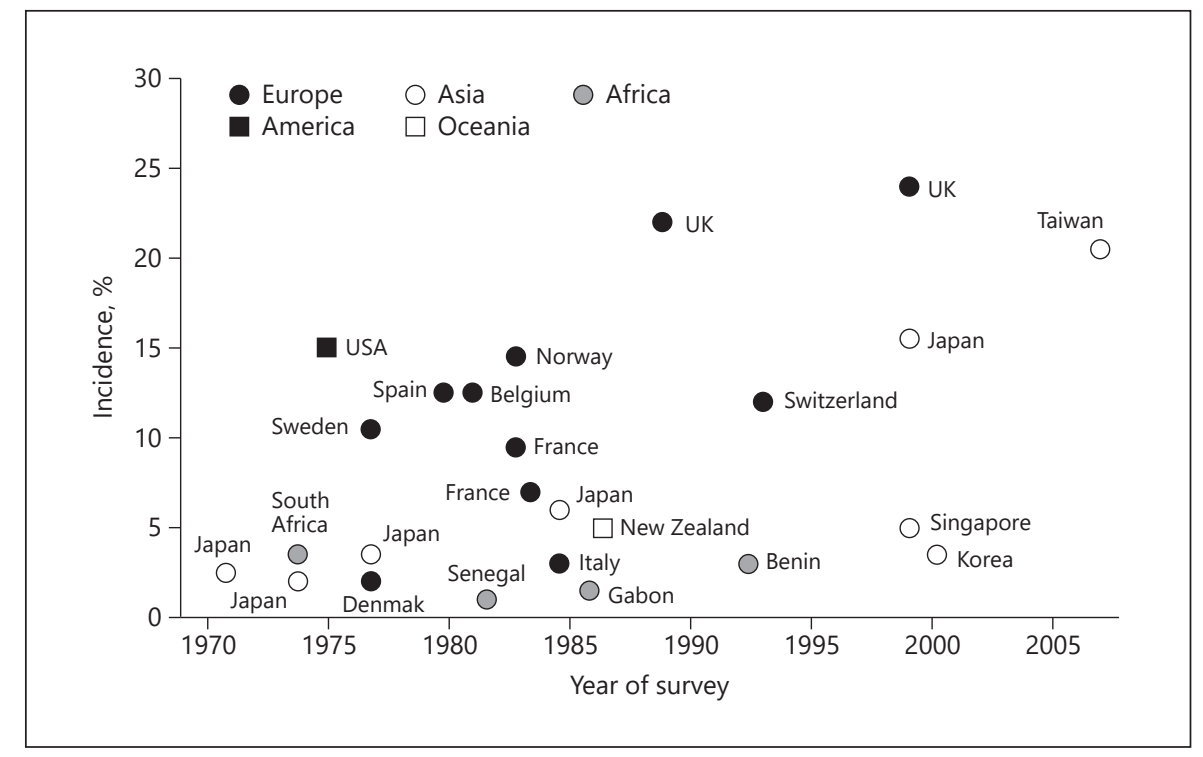

with $H$. pylori infection. McColl described the pathogenesis of GEJ adenocarcinoma in terms of gastric acid secretion and categorized it into 2 types: one that is associated with atrophic gastritis and low gastric acid secretion ( similar to distal gastric cancers) and another type that is associated with excessive acid secretion with or without $H$. pylori infection (similar to esophageal adenocarcinomas) [47].

A large number of patients with chronic gastritis have undergone $H$. pylori eradication therapy in Asian countries, including Japan. It is important to determine whether the incidence of esophageal adenocarcinoma will increase after $H$. pylori eradication therapy, especially in the context of future trends of GEJ adenocarcinoma. Although there is currently no sign of an increase in the incidence of GEJ adenocarcinoma in post-eradication cases in Japan, there is only limited evidence on this issue. Take et al. [48] followed up 2,737 patients after $H$. pylori eradication therapy for an average of 7.1 years and found 2 cases of esophageal adenocarcinoma. They concluded that although the incidence of GEJ adenocarcinoma in patients after $H$. pylori eradication is higher than that in the general population, it is still very low. A previous study also found that the prevalence of esophageal adenocarcinoma is higher with persistent $H$. pylori infection than after eradication therapy, and a recent meta-analysis suggested that $H$. pylori infection may reduce the risk of esophageal adenocarcinoma in the general population. However, these findings may be one-sided; the statement of "protection effect" may be overestimated [49]. At pres- ent, it is reasonable to assume that the widespread use of $H$. pylori eradication therapy for chronic gastritis will not directly lead to an increase in the incidence of esophageal adenocarcinoma and GEJ adenocarcinoma, although further studies are needed to clarify this important issue.

\section{Currently Known Underlying Molecular Mechanisms of GEJ Adenocarcinoma, Especially for Barrett's Esophageal Adenocarcinoma}

Barrett's epithelium changes from an atypical epithelium to a morphologically cancerous epithelium. One of the genes that regulate the cell cycle is p16, and it is classified as a tumor suppressor gene. The p16 gene is frequently altered in the atypical epithelium, which is considered to be in a precancerous stage. In addition to p16, p53 mutations are frequently observed in Barrett's esophageal adenocarcinoma [50]. In long-segment Barrett's esophagus (LSBE) and short-segment Barrett's esophagus (SSBE), adenocarcinoma tends to develop and is characterized by severe inflammation. This suggests the involvement of nuclear factor- $\mathrm{\kappa B}$ and activation-induced cytidine deaminase in carcinogenesis [51]. Chronic inflammation of Barrett's epithelium caused by chronic reflux of gastric acid and/or bile acid leads to the development of Barrett's esophageal adenocarcinoma. Additionally, there is activation of activation-induced cytidine deaminase via nuclear factor- $\kappa \mathrm{B}$, and mutation of $\mathrm{p} 53$, $\beta$-catenin, $c$-myc, and $\mathrm{K}$-ras. 


\section{Differences in the Rate of Carcinogenesis between SSBE and LSBE}

There is a difference in carcinogenesis between the 2 major categories of Barrett's esophagus: SSBE and LSBE. LSBE refers to the presence of Barrett's mucosa $\geq 3 \mathrm{~cm}$ in circumference, whereas SSBE refers to the presence of Barrett's mucosa $<3 \mathrm{~cm}$ in circumference or noncircumferential size. Most cases of Barrett's esophagus in Asian countries are SSBE.

The risk of carcinogenesis of Barrett's esophagus depends on its length. A recent meta-analysis showed that the incidence of carcinogenesis, including high-grade dysplasia, was $0.24 \%$ per year for SSBE and $0.76 \%$ per year for LSBE [52]. The carcinogenesis of Barrett's esophagus involves both genetic instability and clonal expansion. A previous study measured the presence and size of p16 lesions (loss of heterozygosity, mutations, and CpG island methylation), p53 lesions (loss of heterozygosity and mutations), and ploidy abnormalities (aneuploidy and tetraploidy) in 267 patients with Barrett's esophagus who were followed for $>4.4$ years. The size of clones with $p 53$ loss or ploidy abnormalities was found to be more predictive of progression to Barrett's esophageal cancer than only the presence of such clones [53]. Although we cannot deny the possibility that the incidence of SSBE will increase in the future, it is unlikely that there will be an extreme increase in the incidence of LSBE because of the current changes in environmental factors. Therefore, unlike in Western countries, it is likely that the cases of Barrett's esophageal adenocarcinoma based on LSBE will not significantly increase in Asian countries.

\section{Trends in the Incidence of GEJ Adenocarcinoma in Asian Countries}

A review of the trends in the incidence of surgical cases of GEJ adenocarcinoma, including Barrett's esophageal adenocarcinoma, in Japan, has shown that GEJ cancers accounted for only $2.3 \%$ of all gastric cancers from 1962 to 1965 , but this proportion increased to $10.0 \%$ from 2001 to 2005 . This increase was mostly due to an increase in the incidence of Siewert type II esophageal adenocarcinoma [54]. Recent reports in Japan have also reported an increase in the incidence of GEJ cancer, including Barrett's esophageal adenocarcinoma [55].

In the USA, the incidence of esophageal adenocarcinoma has exceeded that of esophageal squamous cell carcinoma in the approximately 20 years since the first report indicating its increase. In Japan, the incidence of esophageal adenocarcinoma has recently increased by $6 \%-7 \%$ [56], but it is not thought to increase at a faster rate than esophageal adenocarcinoma in Western countries. There are several potential reasons for this. First, although the $H$. pylori infection rate in Japan is decreasing, the corresponding increase in the capacity of gastric acid secretion is not necessarily increasing [57]. Second, although the incidence of reflux esophagitis is clearly increasing, the rate of increase over the past 10 years is not high [37]. Third, the degree of obesity in Asian countries is mild compared with that in Western countries, and the trend of BMI has remained almost unchanged in recent decades. Fourth, cases of Barrett's esophagus, one of the originating sites of junctional carcinoma, are mostly categorized as SSBE in most Asian countries, which has much lower carcinogenicity than LSBE. In consideration of arguments, the incidence of GEJ adenocarcinoma, including Barrett's esophageal adenocarcinoma, is expected to increase gradually in the future, but not as rapidly as that in Western countries.

\section{Conclusion}

In general, esophageal adenocarcinoma is positively correlated with socioeconomic development. The incidence of reflux esophagitis and GEJ adenocarcinoma has clearly been increasing in some Asian countries, including Japan, but not as rapidly as in Western countries. Because several differences have already been recognized between Asian and Western countries regarding its pathogenesis and the aforementioned risk factors, it is difficult to apply study results from Western countries directly to the Asian population. From 1988 to 2007, no clear increase in the incidence of esophageal adenocarcinoma in any Asian country has been reported [24]. To be prepared for the medical treatment of GEJ adenocarcinoma, it is necessary to determine the epidemiological trends in Asian countries while referring to those in Western countries.

\section{Acknowledgments}

We thank Edanz (https://jp.edanz.com/ac) for editing a draft of this manuscript.
Manabe/Matsueda/Haruma 


\section{Conflict of Interest Statement}

Noriaki Manabe received honorarium from Takeda Pharmaceutical Company Ltd. and Tsumura \& Co.

\section{Funding Sources}

This study did not receive any external funding.

\section{Author Contributions}

N.M. conceived the study, designed the research, and drafted the manuscript; K.M. and K.M. edited and revised the manuscript; N.M., K.M., and K.H. approved the final version of the manuscript. The authors alone are responsible for the content and writing of the article.

\section{References}

1 Keighley MR. Gastrointestinal cancers in Europe. Aliment Pharmacol Ther. 2003 Nov; 18(Suppl 3):7-30.

2 Chow WH, Finkle WD, McLaughlin JK, Frankl H, Ziel HK, Fraumeni JF Jr. The relation of gastroesophageal reflux disease and its treatment to adenocarcinomas of the esophagus and gastric cardia. JAMA. 1995 Aug 9; 274(6):474-7.

3 Lagergren J, Bergström R, Lindgren A, Nyrén O. Symptomatic gastroesophageal reflux as a risk factor for esophageal adenocarcinoma. $\mathrm{N}$ Engl J Med. 1999 Mar 18;340(11):825-31.

$4 \mathrm{Wu}$ AH, Tseng CC, Bernstein L. Hiatal hernia, reflux symptoms, body size, and risk of esophageal and gastric adenocarcinoma. Cancer. 2003 Sep 1;98(5):940-8.

5 Pohl H, Wrobel K, Bojarski C, Voderholzer W, Sonnenberg A, Rösch T, et al. Risk factors in the development of esophageal adenocarcinoma. Am J Gastroenterol. 2013 Feb;108(2): 200-7.

6 Hasegawa S, Yoshikawa T, Cho H, Tsuburaya $\mathrm{A}$, Kobayashi O. Is adenocarcinoma of the esophagogastric junction different between Japan and western countries? The incidence and clinicopathological features at a Japanese high-volume cancer center. World J Surg. 2009 Jan;33(1):95-103.

7 Huang Q, Fang DC, Yu CG, Zhang J, Chen $\mathrm{MH}$. Barrett's esophagus-related diseases remain uncommon in China. J Dig Dis. 2011 Dec;12(6):420-7.

8 Imamura $\mathrm{Y}$, Watanabe M, Oki E, Morita M, Baba H. Esophagogastric junction adenocarcinoma shares characteristics with gastric adenocarcinoma: literature review and retrospective multicenter cohort study. Ann Gastroenterol Surg. 2021 Oct 26;5(1):46-59.

9 Du X, Hidayat K, Shi BM. Abdominal obesity and gastroesophageal cancer risk: systematic review and meta-analysis of prospective studies. Biosci Rep. 2017 May 11;37(3): BSR20160474.

10 Kim JJ. Epidemiology of gastroesophageal junction adenocarcinoma in Korea. J Gastric Cancer. 2018 Dec;18(4):328-38.

11 Chen YH, Yu HC, Lin KH, Lin HS, Hsu PI Prevalence and risk factors for Barrett's esophagus in Taiwan. World J Gastroenterol. 2019 Jul 7;25(25):3231-41.
12 Blaser MJ. Hypothesis: the changing relationships of Helicobacter pylori and humans: implications for health and disease. J Infect Dis. 1999 Jun;179(6):1523-30.

13 Wang HY, Leena KB, Plymoth A, Hergens MP, Yin L, Shenoy KT, et al. Prevalence of gastro-esophageal reflux disease and its risk factors in a community-based population in southern India. BMC Gastroenterol. 2016 Mar; $15 ; 16: 36$

14 Hung LJ, Hsu PI, Yang CY, Wang EM, Lai $\mathrm{KH}$. Prevalence of gastroesophageal reflux disease in a general population in Taiwan. J Gastroenterol Hepatol. 2011 Jul;26(7):11648.

15 Fujiwara Y, Arakawa T. Epidemiology and clinical characteristics of GERD in the Japanese population. J Gastroenterol. 2009;44(6): 518-34.

16 Deepa M, Farooq S, Deepa R, Manjula D, Mohan V. Prevalence and significance of generalized and central body obesity in an urban Asian Indian population in Chennai, India (CURES: 47). Eur J Clin Nutr. 2009 Feb;63(2): 259-67.

17 Gu D, Reynolds K, Wu X, Chen J, Duan X, Reynolds RF, et al. Prevalence of the metabolic syndrome and overweight among adults in China. Lancet. 2005 Apr 16;365(9468):1398405.

18 Sasazuki S, Inoue M, Tsuji I, Sugawara Y, Tamakoshi A, Matsuo K, et al. Body mass index and mortality from all causes and major causes in Japanese: results of a pooled analysis of 7 large-scale cohort studies. J Epidemiol. 2011;21(6):417-30.

19 Haruma K, Okamoto S, Kawaguchi H, Gotoh T, Kamada T, Yoshihara M, et al. Reduced incidence of Helicobacter pylori infection in young Japanese persons between the 1970s and the 1990s. J Clin Gastroenterol. 1997 Dec; 25(4):583-6.

20 Xia B, Xia HH, Ma CW, Wong KW, Fung FM, Hui CK, et al. Trends in the prevalence of peptic ulcer disease and Helicobacter pylori infection in family physician-referred uninvestigated dyspeptic patients in Hong Kong. Aliment Pharmacol Ther. 2005 Aug 1;22(3): 243-9.
21 Chen J, Bu XL, Wang QY, Hu PJ, Chen MH. Decreasing seroprevalence of Helicobacter pylori infection during 1993-2003 in Guangzhou, southern China. Helicobacter. 2007 Apr;12(2):164-9.

22 Nishi M, Noumura H, Kajisa T, Aiko T, Kaneko Y, Kawaji T, et al. Surgical problem of carcinoma in the esophagogastric junction (in Japanese with English abstract). Stomach Intest. 1978;13:1497-507.

23 Siewert JR, Stein HJ. Carcinoma of the gastroesophageal junction - classification, pathology and extent of resection. Dis Esophagus. 1996;9:173-82.

24 Xie SH, Lagergren J. Time trends in the incidence of oesophageal cancer in Asia: variations across populations and histological types. Cancer Epidemiol. 2016 Oct;44:71-6.

25 Hongo M, Nagasaki Y, Shoji T. Epidemiology of esophageal cancer: Orient to Occident. Effects of chronology, geography and ethnicity. J Gastroenterol Hepatol. 2009 May;24(5): 729-35.

26 Buas MF, Vaughan TL. Epidemiology and risk factors for gastroesophageal junction tumors: understanding the rising incidence of this disease. Semin Radiat Oncol. 2013 Jan; 23(1):3-9.

27 Crane SJ, Richard Locke G 3rd, Harmsen WS Diehl NN, Zinsmeister AR, Joseph Melton L $3 \mathrm{rd}$, et al. The changing incidence of oesophageal and gastric adenocarcinoma by anatomic sub-site. Aliment Pharmacol Ther. 2007 Feb 15;25(4):447-53

28 Gajperia C, Barbiere JM, Greenberg D, Wright K, Lyratzopoulos G. Recent incidence trends and sociodemographic features of oesophageal and gastric cancer types in an English region. Aliment Pharmacol Ther. 2009 Oct 15;30(8):873-80.

29 Rantanen T, Oksala N, Sand J. Adenocarcinoma of the oesophagus and oesophagogastric junction: analysis of incidence and risk factors. Anticancer Res. 2016 May;36(5): 2323-9.

30 Parfitt JR, Miladinovic Z, Driman DK. Increasing incidence of adenocarcinoma of the gastroesophageal junction and distal stomach in Canada: an epidemiological study from 1964-2002. Can J Gastroenterol. 2006 Apr 20(4):271-6. 
31 Forman D. Review article: oesophago-gastric adenocarcinoma: an epidemiological perspective. Aliment Pharmacol Ther. 2004 Oct; 20(Suppl 5):55-2.

32 Lee HS, Jeon SW. Barrett esophagus in Asia: same disease with different pattern. Clin Endosc. 2014 Jan;47(1):15-22.

33 Akiyama $\mathrm{T}$, Inamori $\mathrm{M}$, Akimoto $\mathrm{K}$, Iida $\mathrm{H}$, Mawatari H, Endo H, et al. Risk factors for the progression of endoscopic Barrett's epithelium in Japan: a multivariate analysis based on the Prague C \& M Criteria. Dig Dis Sci. 2009 Aug;54(8):1702-7.

34 Japan Esophageal Society. Japanese classification of esophageal cancer, 11th edition: part II and III. Esophagus. 2017;14(1):37-65.

35 Ishimura N, Amano Y, Sollano JD, Zhu Q, Kachintorn U, Rani AA, et al. Questionnairebased survey conducted in 2011 concerning endoscopic management of Barrett's esophagus in East Asian countries. Digestion. 2012; 86(2):136-46.

36 Wang KK, Sampliner RE. Practice parameters committee of the American college of gastroenterology. Updated guidelines 2008 for the diagnosis, surveillance and therapy of Barrett's esophagus. Am J Gastroenterol. 2008 Mar;103(3):788-97.

37 Takubo K, Aida J, Naomoto Y, Sawabe M, Arai T, Shiraishi $\mathrm{H}$, et al. Cardiac rather than intestinal-type background in endoscopic resection specimens of minute Barrett adenocarcinoma. Hum Pathol. 2009 Jan;40(1):6574.

38 Hasegawa S, Yoshikawa T. Adenocarcinoma of the esophagogastric junction: incidence, characteristics, and treatment strategies. Gastric Cancer. 2010 Jun;13(2):63-73.

39 Siewert JR, Stein HJ, Feith M. Adenocarcinoma of the esophago-gastric junction. Scand J Surg. 2006;95:260-9.

40 Matsuhashi N, Sakai E, Ohata K, Ishimura N, Fujisaki J, Shimizu T, et al. Surveillance of patients with long-segment Barrett's esophagus: a multicenter prospective cohort study in Japan. J Gastroenterol Hepatol. 2017 Feb;32(2): 409-14.
41 Matsueda K, Manabe N, Toshikuni N, Sato Y, Watanabe $\mathrm{T}$, Yamamoto $\mathrm{H}$, et al. Clinical characteristics and associated factors of Japanese patients with adenocarcinoma of the esophagogastric junction: a multicenter clinicoepidemiological study. Dis Esophagus. 2017 Jun 1;30(6):1-6.

42 Murao T, Sakurai K, Mihara S, Marubayashi T, Murakami Y, Sasaki Y. Lifestyle change influences on GERD in Japan: a study of participants in a health examination program. Dig Dis Sci. 2011 Oct;56(10):2857-64.

43 Fujiwara Y. Recent epidemiology of GERD in the Japanese population. Nihon Shokakibyo Gakkai Zasshi. 2017;114(10):1781-9.

44 McQuaid KR, Laine L, Fennerty MB, Souza R, Spechler SJ. Systematic review: the role of bile acids in the pathogenesis of gastro-oesophageal reflux disease and related neoplasia. Aliment Pharmacol Ther. 2011 Jul;34(2):146-65.

45 Kato M, Asaka M, Shimizu Y, Nobuta A, Takeda H, Sugiyama T, et al. Relationship between Helicobacter pylori infection and the prevalence, site and histological type of gastric cancer. Aliment Pharmacol Ther. 2004 Jul;20(Suppl 1):85-9.

46 Kamada T, Kurose H, Yamanaka Y, Manabe N, Kusunoki H, Shiotani A, et al. Relationship between gastroesophageal junction adenocarcinoma and Helicobacter pylori infection in Japan. Digestion. 2012;85(4):256-60.

$47 \mathrm{McC}$ oll KE. Cancer of the gastric cardia. Best Pract Res Clin Gastroenterol. 2006;20(4): 687-96.

48 Take S, Mizuno M, Ishiki K, Hamada F, Yoshida T, Yokota K, et al. Low incidence of esophageal adenocarcinoma after eradication of Helicobacter pylori in Japan. Clin Gastroenterol Hepatol. 2018 Dec;16(12):1995-6.

49 Gao H, Li L, Zhang C, Tu J, Geng X, Wang J, et al. Systematic review with meta-analysis: association of Helicobacter pylori infection with esophageal cancer. Gastroenterol Res Pract. 2019 Dec 1;2019:1953497.
50 Binato M, Gurski RR, Fagundes RB, Meurer L, Edelweiss MI. P53 and Ki-67 overexpression in gastroesophageal reflux disease Barrett's esophagus and adenocarcinoma sequence. Dis Esophagus. 2009;22:588-95.

51 Fitzgerald RC, Abdalla S, Onwuegbusi BA, Sirieix P, Saeed IT, Burnham WR, et al. Inflammatory gradient in Barrett's oesophagus: implications for disease complications. Gut. 2002;51:316-22.

52 Chandrasekar VT, Hamade N, Desai M, Rai T, Gorrepati VS, Jegadeesan R, et al. Significantly lower annual rates of neoplastic progression in short- compared to long-segment non-dysplastic Barrett's esophagus: a systematic review and meta-analysis. Endoscopy. 2019;51:665-72.

53 Maley CC, Galipeau PC, Li X, Sanchez CA, Paulson TG, Blount PL, et al. The combination of genetic instability and clonal expansion predicts progression to esophageal adenocarcinoma. Cancer Res. 2004 Oct 15; 64(20):7629-33.

54 Kusano C, Gotoda T, Khor CJ, Katai H, Kato $\mathrm{H}$, Taniguchi $\mathrm{H}$, et al. Changing trends in the proportion of adenocarcinoma of the esophagogastric junction in a large tertiary referral center in Japan. J Gastroenterol Hepatol. 2008 Nov;23(11):1662-5.

55 Matsuno K, Ishihara R, Ohmori M, Iwagami $\mathrm{H}$, Shichijyo S, Maekawa A, et al. Time trends in the incidence of esophageal adenocarcinoma, gastric adenocarcinoma, and superficial esophagogastric junction adenocarcinoma. J Gastroenterol. 2019 Sep;54(9):784-91.

56 Nishi T, Makuuchi H, Ozawa S, Shimada H, Chino O. The present status and future of Barrett's esophageal adenocarcinoma in Japan. Digestion. 2019;99(2):185-90.

57 Ishimura N, Owada Y, Aimi M, Oshima T, Kamada $\mathrm{T}$, Inoue $\mathrm{K}$, et al. No increase in gastric acid secretion in healthy Japanese over the past two decades. J Gastroenterol. 2015 Aug; 50(8):844-52. 